\title{
Video-Juegos y performatividad del concepto de mujer en Educación Artística-Plástica en la Infancia, en Chile
}

\author{
Marta Ríos Chandía martitarios@gmail.com \\ Luis Claudio Cortes Picazo luis_clecu@yahoo.com \\ Universidad Autonoma de Chile, Chile
}

Reference

Chandía, Marta Ríos; Picazo, Luis Claudio Cortes; (2012) "Video-Juegos y performatividad del concepto de mujer em Educación Artística-Plástica en la Infancia, en Chile", p. 179-185. In: Barbosa, Helena; Quental, Joana [Eds]. Proceedings of the 2nd International Conference of Art, Illustration and Visual Culture in Infant and Primary Education. São Paulo: Blucher 2015. ISSN 2318-695X, ISBN: 978-989-98185-0-7 DOI 10.5151/edupro-aivcipe-35

Este artículo da cuenta de una experiencia de investigación colaborativa entre docentes en su etapa inicial de formación y formadores de docentes, la cual se llevó a cabo durante el mes de mayo de 2012 en cinco establecimientos educacionales urbanos y rurales de la región del Maule, Chile.

Centramos la experiencia de investigación en dos objetivos fundamentales, uno de ellos fue describir a partir del análisis de las evidencias obtenidas, los conceptos o cambios performativos que niños/as poseen sobre los modos de ver y representar a la mujer protagonista de vídeojuegos, el otro consistió esencialmente en acercar y desarrollar junto a los/as alumnos/as de la carrera de Pedagogía en Artes Visuales un proceso de investigación educativa colaborativa, que les permita introducirse en este ámbito. A grandes rasgos presentaremos los resultados de ésta experiencia que llega a la conclusión que la cultura visual es una herramienta valiosa y necesaria de incorporar en la educación artística tanto a nivel escolar, como a nivel de formación de profesores en Chile.

Video-Games, Concept of Woman, Performativity, Arts Education in Chile

\section{Abstract}

This article reports an experience of collaborative research between teachers in theirearly training and teacher trainers, which took place during the month of May 2012 in five urban and rural educational institutions in the region of Maule, Chile.

Research experience focused on two main objectives, one of which was described from analysis of the evidence obtained, or changes performative concepts that children haveabout the ways of seeing and representing the female protagonist of video-game, the other was essentially closer and develop together with the students of the career ofVisual Arts Education in a collaborative educational research process, enabling them toventure into this field. Roughly present the results of this experience I concluded that visual culture is a valuable and necessary to incorporate arts education both at schooland at the level of teacher training in Chile.

Keywords

\section{Como iniciamos el recorrido}

Junto a los treinta alumnos/as de segundo año de la carrera de Pedagogía en Artes Visuales de la Universidad Autónoma de Chile sede Talca, nos planteamos el desafío de responder a algunas de las interrogantes e inquietudes que surgían de los diversos diálogos y reflexiones que establecíamos en las clases de Didáctica I, uno de ellos fue la abrumadora presencia de la imagen en la sociedad actual y como los niños/as de Chile, y todos en general éramos 
consumidores pasivos y en algunos casos analfabetos de la cultura visual, Freedman (2006) señala que ésta puede ser vista como una ayuda segura, creativa y como parte integral del conocimiento y de igual modo como perjudicial, peligrosa y destructiva para la sociedad.

Quisimos aprovechar las instancias de acceso al contexto escolar local que tienen los/as alumnos/as en el presente semestre, para iniciar este primer acercamiento a un proceso de investigación colaborativa. Nos planteamos como tema central la performatividad que ha generado el uso y consumo de los Video-Juegos en las formas de ver, describir y representar el concepto de mujer protagonista de éstos. Se utilizó la metodología cualitativa, descriptiva e interpretativa, y para la recolección de las evidencias, se efectuaron entrevistas estructuradas' y se recogieron las representaciones gráficas de sesenta y un niños/as pertenecientes a $6^{\circ}$ año básico.

En relación al contexto escolar, Freedman (2006:13) señala que es "importante ayudar a los alumnos a estudiar la variedad de significados, más que intentar protegerles de la imaginería”. Al respecto Walker, J y Chaplin S. (2002: 17) exponen que es relevante "prestar atención a las características visuales de las artes visuales y los medios de comunicación de masas". Por lo general en el contexto educativo formal los niños/as solo se vinculan con las artes visuales desde un punto vista estético, las imágenes provenientes de los medios de comunicación de masas no tienen cabida en el currículum formal. Es por ésto, que consideramos que los futuros docentes de Artes Visuales deben incorporar y centrar su atención hacia las caracteristicas visuales que están presentes en el entorno y en los intereses de los niños/as, puesto que estamos insertos en "una era de choques culturales y de conexiones transculturales que motivan y enriquecen el aprendizaje del alumno mediante las imágenes visuales y los objetos de la vida cotidiana" (Freedman, 2006:11).

Los alumnos/as en este nivel de formación, se insertan por primera vez al contexto escolar a través de las prácticas progresivas, éstas iniciales inserciones consisten en realizar observaciones, observaciones participantes y entrevistas en el aula a la cual se insertan. Consideramos que es importante que ellos/ellas aprovechen esta estancia, como una herramienta que les permita acercarse al mundo de la investigación desde los primeros años de formación, para que en el futuro ya como docentes, puedan ser agentes activos y gestores de investigación educativa, esencialmente desde las Artes Visuales.

Asumimos que tenemos un gran desafío como país y como educadores de Artes Visuales, debemos educar e incorporar la Cultura Visual y el enfoque de Género en la formación de profesores, en el contexto escolar y en el curriculum formal de Educación Artística. ${ }^{2}$

\section{Fundamentándo nuestras ideas}

En esta última década, en América Latina, el Caribe y en Europa, la educación artística ha intentado incorporar la mediación cultural, la cultura visual y la lectura de imágenes, así mismo ha pretendido promover el desarrollo de la capacidad crítica-reflexiva, ante el modelo reinante de escuela reproductiva. En el Congreso de INSEA (International Society for education through art) efectuado en el año 2007, así mismo en el Congreso Iberoamericano de Educación Artística desarrollado en el año 2008, se señala que una educación artística a-crítica no responde a las exigencias de los nuevos aprendizajes, ambos plantean en sus propuestas que es importante revisar críticamente los programas curriculares, con el objetivo de incluir las contribuciones más recientes de los estudios culturales, la cultura visual y la cognición imaginativa. Apuntan a ir más allá de la lectura de imágenes y la apreciación estética, de modo de ir avanzando hacia la comprensión crítica de la Cultura Visual. Así mismo en el $7^{\circ}$ Congreso Internacional de Arte, Ilustración y Cultura Visual, en Educación Infantil y Primaria efectuado en el 2010, se plantearon como temática centrales las construcciones e identidades de género, tras criterios estéticos y formales utilizados en la producción de obras para niños y niñas, así como los discursos relacionados con el arte, la ilustración y las imágenes que representan, exploran y configuran la idea de infancia.

1 Las entrevistas estructuradas se desarrollaron en focus group, de modo de crear una participación más interactiva de parte de los niños/as igualmente los estudiantes-docentes se distribuyeron en parejas y/o tríos de entrevistadores/as, de modo que uno de ellos documentara el proceso y el otro/a dirigia la entrevista y el diálogo del grupo.

22 Así mismo intentar derogar el decreto 1363 planteado por el Ministerio de Educación, que dictamina la reducción de horas de Educación Artística (Artes Visuales y Musicales) para la educación secundaria, a partir del año 2013 
2nd International Conference Art, Illustration and Visual Culture in Infant and Primary Education $2^{\circ}$ Congreso Internaciona

Arte, Ilustración y Cultura Visual en Educación Infantil y Primaria $2^{\circ}$ Congresso Internacional

de Arte, llustracão e Cultura Visual

na Educação Infantil e Primária

En este sentido, la INSEA (2011) fomenta la comprensión de la Cultura Visual a partir de la construcción del género y sus representaciones de raza, sexualidad, edades, discapacidades y clases sociales, con el objeto de promover el diálogo sobre Cultura Visual y Género. Refiriéndose de este modo a los procesos de enseñanza aprendizaje y a las prácticas utilizadas, que exponen significados culturalmente aprendidos y construidos, así como las relaciones de poder que rodean a la creación, el consumo, la valoración y la difusión de imágenes.

En Chile, tras la Reforma Educacional implementada a inicio de los años noventa, se detectan ciertos intentos por actualizar los contenidos y objetivos contemplados en el currículum de educación artística. Sin embargo, se perciben desventajas en relación a los aportes internacionales recién mencionados, que promulgan la incorporación de los contenidos alusivos a la Cultura Visual y a la perspectiva de Género. Es lamentable que en el contexto de la reforma educacional y del sistema escolar chileno, el nombre del área o sector de aprendizaje que dice relación con las artes visuales solo fue modificado en su nombre, menos en su contenido y formas de hacer en la práctica.

Es importante visualizar las influencias de los medios de comunicación e imágenes del entorno bajo la perspectiva de análisis crítico, así mismo los roles que debemos asumir como consumidores y espectadores de imágenes provenientes de la cultura visual. Chen y Kantner 1996 (citado en Hernández M. y Sánchez M., 2000:16) señalan que la variable de género como objeto de estudio y desde una perspectiva feminista, plantea que las representaciones y significados otorgados al concepto de mujer a través de la expresión gráfica, permiten profundizar las diferencias de género a partir de la distinción entre dibujos realizados por niños y niñas. Así mismo es relevante considerar las influencias del ámbito familiar, educacional y mediático que adoptan los niños y niñas a través de sus dibujos (Maeso B., 2008). Según un estudio de Kindler y Darras (1994) (citado en Hernández M. y Sánchez M, 2000) el dibujo infantil y adolescente se presenta como una verdadera obra multimedial de la que forman parte gestos, sonidos, expresiones corporales y comentarios verbales, en general rasgos relevantes del contexto en el que se produce la representación gráfica.

La masculinización de la mujer en la Cultura mediática, demanda atender el proceso de transformación del concepto construido y establecido, social y tradicionalmente de la mujer en ésta era de la digitalización y de la información, preconizada por McLuhan (2005), tras lo cual se procede a desbordar los límites de la dicotomía sexo-género, mente-cuerpo, realidad-apariencia, según lo planteado en el manifiesto Cyborg (Haraway, 1991), así mismo bajo el pensamiento feminista queer (Butler, 2005). La presencia de las nuevas tecnologías en todos los aspectos de la vida actual, requiere de una redefinición del concepto y de la identidad de la mujer, la hibridación es una de las características principales de la civilización actual y sobre todo del concepto de mujer, en el que se concentran distintas identidades y roles sociales, sin fundirse en una unidad homogénea.

Al respecto, para desvelar las construcciones de género que emiten los medios digitales de comunicación, tales como los video-juegos (Gil y Vall-llovera, 2009), los cuales en definitiva son consumidos por niños/as y jóvenes, es necesario exista desde el contexto escolar una abertura hacia los estudios de cultura visual. No se trata de abrir sus contenidos por ejemplo a las manifestaciones populares, sino que se trata de afrontar un desafío de mayor profundidad, es decir adquirir un alfabetismo visual crítico, que permita a los niños/as y adolescentes analizar, interpretar, evaluar y crear a partir de la relación de los saberes, en especial los vinculados a las imágenes que saturan las representaciones tecnologizadas de la sociedades contemporáneas (Hernández F. 2007).

De este modo, el presente artículo atiende a la construcción y transformación del concepto de mujer, la cual es presentada de acuerdo a estereotipos de sexo y género predominantes en los video-juegos digitales, inmersos en la Cultura Visual de los niños/as y jóvenes, tales como Lara Croft, Final Fantasy y Dead or Alive (Mendizábal, 2004), de modo de establecer una relación e interpretación de las características incorporadas en la expresión oral y gráfica de los niños/ as participantes en el estudio. Haciendo eco de este modo, a las sugerencias planteadas en el I Congreso Internacional de Arte, Ilustración y Cultura Visual en Educación Infantil y Primaria efectuado en el año 2010, en que se abordó la noción de mujer que transgrede las dicotomías de sexo y género desprendidas del análisis crítico-reflexivo y solventado por el pensamiento 
feminista posmoderno (Haraway 1991, 2004; Fantone 2003; Jones 2003; Butler 2005). En el III Congreso de arte infantil realizado en el año 2005 en la Universidad Complutense de Madrid, Wilson discute sobre las ventajas educativas del uso del manga japonés (dojinshi), en establecimientos educacionales de primaria y secundaria, lo ubica en un escenario pedagógico intermedio, denominado modalidad de pedagogía transaccional. Dicho escenario se define como una transacción continua de valores e ideas entre profesores y estudiantes mediante al intertextualidad de textos visuales provenientes de la cultura visual. De hecho, el ámbito del consumo cultural de tales productos cobra relevancia al momento de describir nuevas estructuras sintácticas, cognitivas y perceptivas de la micro-cultura infanto-juvenil, entrando en desequilibrio con las estrategias de la institucionalización de la enseñanza. Las propuestas de las nuevas tecnologías y de la video-animación implicarían nuevas formas de mirar, de percibir y de conocer aquellos aspectos, que no son tomados en cuenta en el proceso de enseñanzaaprendizaje, el cual está basado esencialmente en una cultura tradicional de raigambre más lingüística que visual (Villar, 2000).

En el desafío planteado por la teoría feminista frente a la cultura visual, surgen actos performativos de deconstrucción de las identidades cerradas y estereotipadas, dando lugar a identidades nómadas y fluctuantes. Gil y Vall-Ilovera (2009), señalan que el surgimiento de la desestigmatización de las identidades, parte del hecho de la no adaptación a normativas culturales predominantes como la heterosexualidad imperante o la dicotomía femenino/ masculino. Haraway (1991-2004) en este sentido, invita a explorar y vivir modelos de existencia distintos a los preestablecidos, tales como los generados en el mundo virtual. Así por ejemplo, tras el mundo de los videojuegos es decir de los video-jugadores/as, esencialmente aquellos que usan juegos online e interactúan con otros jugadores/as, se observan que dejan de ser seres humanos para convertirse en cyborgs. Este mundo virtual está regido por normas que saben seguir sus habitantes, los cuales al tener el conocimiento de que dicho mundo es una ficción, pueden subvertir y modificar las identidades de género, traspasando las fronteras en los términos planteados por Butler (2005).

Haraway (1991), señala que un cyborg es un organismo cibernético, un híbrido de máquina y organismo, una criatura de la realidad social, así como una criatura de ficción:

\footnotetext{
...una fusión de lo orgánico y lo tecnológico fraguada en prácticas culturales e históricas determinadas. Los cyborgs no tratan de la máquina y lo humano, como si en el universo existieran estas cosas y sujetos. Por el contrario, los cyborgs tratan sobre la interacción de máquinas y personas históricas específicas, que muchas veces acaban siendo penosamente contra-intuitivas para quien analiza la tecno-ciencia. (Haraway, 2004, p.69)
}

El cyborg es una cuestión de ficción en la medida que se transforma en una experiencia viva que cambia, la cual se vierte como experiencia de las mujeres en el siglo XX. De hecho, los movimientos internacionales de mujeres han construido la experiencia de las mujeres, así como descubierto su objetivo colectivo y crucial. Esta experiencia es una ficción en la medida que el cyborg se aproxima virtualmente a la realidad. Se entrecruza con el aspecto político de los movimientos feministas. Tras lo cual, se desprende la liberación de la mujer mediante la construcción de la conciencia, la lucha por la vida y la muerte, entre el límite de la ciencia ficción y la realidad social. El cyborg, en definitiva es una ilusión óptica que atiende las necesidades de deconstrucción de las dicotomías de sexo y género, cuestionando la heterosexualidad predominante.

Es por eso que en un mundo dominado por dispositivos visuales y tecnologías de la representación, la finalidad educativa debiera ser facilitar experiencias reflexivas y críticas, que les permitan a los niños/as y adolescentes, comprender como las imágenes influyen en sus pensamientos, acciones, sentires y en la construcción de su identidad personal y social (Hernández 2007).

\subsection{Los Objetivos, sujetos de estudio y análisis de las evidencias}

Los objetivos que condujeron en nuestro recorrido fueron:

- Describir los conceptos performativos que niños/as poseen sobre los modos de ver y representar a la mujer protagonista de video-juegos mediante la expresión oral y gráfica. 
$2^{\text {nd }}$ International Conference Art, Illustration and Visual Culture in Infant and Primary Education $2^{\circ}$ Congresso Internacional

de Arte, llustracão e Cultura Visual

na Educação Infantil e Primária

- Acercar y desarrollar junto a los/as alumnos/as de la carrera de Pedagogía en Artes Visuales una investigación educativa colaborativa, que les permita introducirse en éste ámbito.

Las cinco escuelas a la cuales accedieron los/as alumnos/as (en duos y tríos) son Municipalizadas, tres de ellas están situadas en contextos urbanos y las dos restantes en contextos rurales, todas pertenecientes a la región del Maule, VII Región. Las edades de los/ as (61) niños/as fluctuan entre 10 y 12 años, algunos están terminando la educación primaria y otros iniciando la secundaria en Chile. Para realizar las entrevistas estructuradas preparamos siete preguntas, las cuales apuntan al conocimiento y descripción de una protagonista de videojuegos digitales.

Posterior a ésta recolectamos las representaciones gráficas que cada uno/a realizaba sobre su protagonista.

De lo anterior se desprenden dos tipos de grupos asociados a la cantidad de integrantes y contextos a los cuales los/as niños/as pertenecen. El primer grupo (véase figura 1 y 2) está conformado preferentemente por cuatro integrantes, los cuales conservan la paridad en términos de género (dos niñas y dos niños), éstos grupos están insertos en ámbitos urbanos y rurales, el segundo grupo está conformado por una cantidad superior de cuatro integrantes, con una evidente variedad de sus integrantes en términos de género, igualmente están inmersos en establecimientos educacionales ubicados en contextos urbanos y rurales.

Figuras 1 y 2.Focus Group de niños y niñas del $7^{\circ}$ básico del Liceo Abate Molina, Talca, Chile (mayo de 2012).

Una vez recogidas las evidencias efectuamos el análisis (en la asignatura de Didáctica I) bajo el enfoque descriptivo e interpretativo, abordando aspectos de la perspectiva crítica de género. Nos centramos esencialmente en las entrevistas, las cuales fueron revisadas a través de vídeos y registros de audio. En el inicio de la experiencia establecimos categorías de análisis, las cuales al transcurrir la investigación fueron omitidas, ya que al recibir las opiniones del par evaluador (en que nos señalaba que las categorías de análisis pre-establecidas impiden adentrarse de manera abierta en construcciones de significados de los sujetos colaboradores), así mismo a la luz de los resultados, consideramos que era más enriquecedor y pertinente para la investigación que éstas surgieran de los propias opiniones de los niños/as, de modo de identificar e interpretar desde sus propios relatos la performatividad, los distintos modos de ver y representar a la mujer protagonista de video-juegos.

Cabe señalar que los niños y niñas insertos en contextos rurales ante el escaso conocimiento, acceso y uso de los video-juegos, señalan y describen mujeres protagonistas bajo el rol de heroínas que surgen en los dibujos animados y series de televisión abierta, entre ellas sobresalen: Shion, Kojiroh, Kula y Chizuru de King of Fighter, todas protagonista de dibujos animados japoneses, sumado a las recurrencias manifestadas en las representaciones gráficas realizadas por las niñas a diferencia de los niños. En aquellos grupos situados en contextos urbanos, la descripción de mujeres protagonistas de video-juegos obedecen a una evidente familiarización con el nombre de las heroínas y el video-juego al cual pertenecen, destacando entre ellas Peach de Mario Kart, Skarlet de Mortal Kombat, Mujer Maravilla (véase figura 3) y Black Yidell de los Vengadores.

En dos grupos se percibe una cierta dependencia entre las niñas, para representar a su heroína y destacan mayoritariamente la representación de heroínas que reflejan arquetipos de mujeres románticas y sensibles tales como Bombón (véase figura 4) y Frutillita, a diferencia de los niños de ambos grupos, quienes manifiestan menor grado de dependencia entre uno y otros, prefiriendo verbalizar y representar gráficamente aquellas figuras femeninas que no obedecen al canon social tradicional de mujer, como por ejemplo: Sonya de Mortal Combat (véase figura 5), Kula de Street Fighter, Relilet (véase figura 6) y Tom Raider, las cuales se caracterizan por representar a una mujer segura, fuerte y testaruda, con obstinación y orgullo, encarnando plenamente las características que promueve una sociedad occidental y posmoderna: el culto al cuerpo, la perfección física, la determinación, la independencia y la búsqueda de emociones intensas, la negación de un estilo de vida sedentario, dónde la estética es el factor dominante. 6

Figura 3. José Pablo (11 años) 
2nd International Conference Art, Illustration and Visual Culture in Infant and Primary Education de Arte, llustração e Cultura Visual

na Educação Infantil e Primária

Figura 4. Constanza (10 años)

Figura 5. Sergio Ignacio (11 años)

Figura 6. Patricio Javier (10 años)

Gil y Vall-Ilovera (2009), señalan respeto al cruce de identidades y la anulación de la dicotomía de sexo y género que Lara Croft de Tom Raiders, permite a los/las video-jugadores apropiarse y resignificar lugares, y personajes femeninos estereotipados. De este modo, el espacio virtual generado por los videojuegos pone en entredicho los deseos masculinos (ciber adolescentes masculinos), al ser objeto de una práctica de subversión de identidades y de roles tradicionales de género. Al igual que en Street Fighter o Soul Caliburm en los que al establecerse una oposición binaria de estereotipos, ninguno queda subyugado a otro, ya que todos los y las personajes tiene las mismas posibilidades de ganar el combate, con el objetivo de asegurar que dicho espacio virtual no da lugar a la resignificación y conservación de los roles tradicionalmente construidos del género.

\section{Concluyendo}

Podemos concluir a partir de esta experiencia de investigación participativa y colaborativa que fue muy enriquecedor y significativo para los futuros docentes de Artes Visuales y para nosotros como formadores, el haber tenido la posibilidad de construir en conjunto ésta investigación, ya que consideramos que es a través de éstas experiencias que se generan aprendizajes, así mismo se aproximan a la investigación de un modo más cercano, aprovechando al máximo las diversas instancias de acceso al campo de estudio que tienen en el transcurso de la carrera. De igual modo en un futuro cercano ya como docentes, podrán adquirir ésta práctica como habitual, para que puedan permanentemente establecer reflexiones e interpretaciones sobre sus prácticas pedagógicas y los procesos que se llevan a cabo en la escuela.

Por otro lado consideramos a la luz de los resultados obtenidos, que los niños/as han ido incorporando y modificando gradualmente su forma de ver a los héroes de los videos juegos, han integrado a la mujer como protagonista heroica, de diversos video juegos o series de dibujos animados, lo cual ha generado un cambio en las formas de ver y representar el concepto de mujer en el contexto escolar en el cual se desarrollo el estudio. Recogiendo la opinión de diversos autores (Mendizábal, 2004) consideramos que en la sociedad chilena y en la sociedad en general se partía y se parte solo del hecho que los hombres son siempre los protagonistas, más aún en los video juegos.

De igual modo es importante señalar que a partir del análisis de las entrevistas y dibujos de los niños/as, que la mujer se está incorporando gradualmente en el terreno que tradicionalmente ha sido ocupado y destinado a los hombres, los niños/as identifican diversos rasgos catalogados como masculinos y femeninos en las protagonistas de los video-juegos, es decir la mujer se masculiniza traspasando su género y convirtiéndose en cyborg. Los conceptos y formas que niños/as construyen, describen y representan gráficamente, aluden mayoritariamente al sesgo androcéntrico al enfatizar el género femenino desde una posición masculina. Por ende, la noción de mujer se solapa y neutraliza bajo la noción masculina de sujeto protagonista en los video-juegos.

\section{Referencias bibliográficas}

Aguirre, I. (2000). Teorías y Prácticas en Educación Artística. Pamplona: Universidad Pública de Navarra. Butler, J. (2004). Deshacer el Género. Barcelona: Paidós.

Butler, J. (2005). Cuerpos que importan. Sobre los límites materiales y discursivos del sexo. Buenos Aires: Paidós.

Butler, Judith. (1999). El Género en Disputa. El Feminismo y la Subversión de la identidad. Barcelona: Paidós. Congreso INSEA (2007). Formación artística y cultural para la Región de América Latina y el Caribe. http:// www.consejodelacultura.cl/portal/galeria/text/text1813.pdf 
$2^{\circ}$ Congresso Internacional

de Arte, Ilustração e Cultura Visual

na Educação Infantil e Primária

Fantone, L. (2003). Final Fantasies: Virtual Women's Bodies. Feminist Theory, 4, 51-72.

Freedman, K.(2006). Enseñar la cultura visual. Currículum, estética y la vida social del arte. Octaedro. España.

Gil, A. y Vall-llovera, M. (2009). Género, Tic y Videojuegos. Barcelona: UOC.

Haraway, D. (1991). A Cyborg Manifesto: Science, Technology, and Socialist-Feminism in the Late Twentieth Century, in Simians, Cyborgs and Women: The Reinvention of Nature (New York; Routledge, 1991), pp.149-181. Obtenido el 01 de febrero de 2012 desde http://www.stanford.edu/dept/HPS/Haraway/ CyborgManifesto.html

Haraway,D.(2004).Testigo_Modest@Segundo_Milenio.HombreHembra@_Conoce_Oncoratón®. Feminismo y tecnociencia. Barcelona: UOC.

Hernández F. (2007). Espigadores/as de la cultura visual. Otra narrativa para la educación de las Artes Visuales. Barcelona. Octaedro.

Hernández, M. y Sánchez, M. (2000). Educación artística y arte infantil. Madrid: Fundamentos.

I Congreso Internacional: Arte, Ilustración y Cultura Visual en Educación Infantil y Primaria (2010).

Construcción de identidades. http://www.congresoarteilustracion.org

III Congreso de arte infantil, U.C.M. (2005). Arte infantil y cultura visual. Madrid: Eneida.

Jones. A. (2003). The Feminism and Visual Cultura reader. London and New York: Routledge.

Maeso, A. (2008). Influencia de la ámbitos familiar, educacional y mediático en la adopción de identidades por los niños y las niñas a través de sus dibujos. Arte, Individuo y Sociedad, 20, 107-128.

McLuhan, M. (2005). Comprender, los medios de comunicación. Barcelona: Paidós.

Mendizábal, R. (2004). Máquinas de pensar. Video juegos, representaciones y simulaciones del poder. Quito: Universidad Andina Simón Bolivar. Ecuador.

Walker, J y Chaplin S. (2002). Una introducción a la cultura visual. Octaedro-EUB. España. 